point) quite accounts for the absence of actual gland-like acini.

Remarks by Professor Hellier.-Adenomyomata have been recognised as a group separate from ordinary myomata for several years, The first important publication on the subject was by Professor von Recklinghausen in 1896, but we are indebted to a very beautiful monograph by Dr. T. S. Cullen, of the Johns Hopkins University (1908), for the best recent work on the subject. Recklinghausen held that the gland structures are derived from vestigial remains of the Wolffian ducts, but Cullen has shown that the gland spaces can be traced to the uterine cavity, and that they are, in fact, offsets from the main uterine canal and communicate with it. It has been shown that menstrual fluid is excreted in these subsidiary glandular spaces, and that in one case, at least, the decidua of pregnancy has been observed in the glandular spaces.

Hence we have a very interesting conception of the uterus in this and similar cases, if we regard the corpus uteri as

FIG. 3.

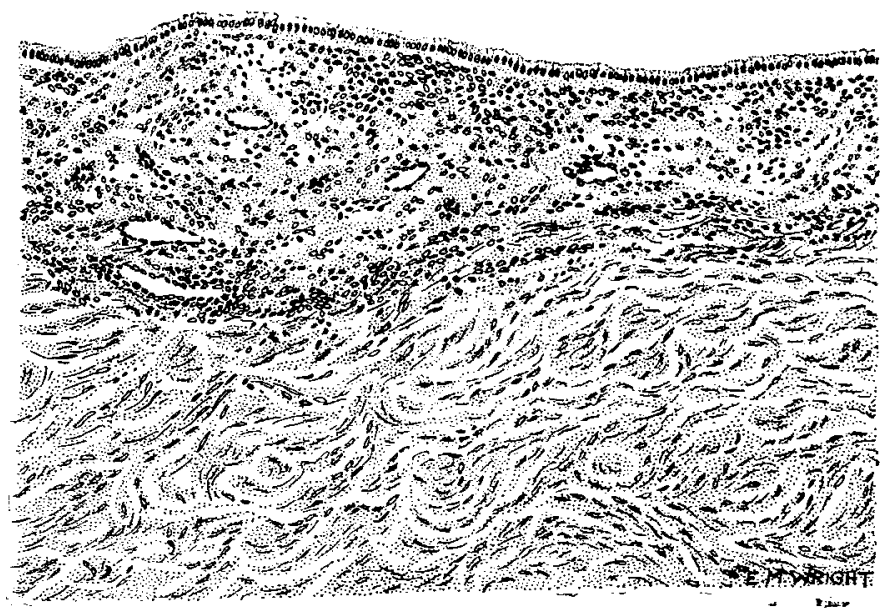

A portion of the margin of one of the larger cystic spaces showing similar appearances to those in Fig. 2. (Figs. 2 and 3

are from drawings by Miss E. Wright.)

more or less penetrated in all directions by small diverticula from the central cavity, with an endometrial lining which takes part in the menstrual function and shares in the physiological changes of pregnancy.

Amongst the clinical features common in adenomyoma Cullen mentions pain at the periods and marked menstrual excess, but this case shows that such features are not invariable. It also illustrates the fact, well known to gynæcologists, that retention of urine is often an important symptom in myoma uteri, and should always be thought of when retention occurs apart from pregnancy or other obvious cause. It is also an important indication for operating for the myoma. Some traces of old peritonitis were found in the pelvis, and this seems common in adenomyoma.

It seems possible, in view of the endometrial diverticula found in these cases, that an ovum might become embedded in the nterine wall and so give rise to an ectopic interstitial pregnancy at a point distant from the interstitial part of the oviduct.

Leeds.

Donations and Bequests.-The late Mrs. Annie Ethel Perrin left for charitable purposes - $\$ 16,000$ divided into 17 parts, of which the Swansea Hospital, the Royal Ear Hospital, London, the Bristol Royal Infirmary, the Bristol General Hospital, the Bristol Dispensary, the Bristol Eye Hospital, the Bristol Hospital for Women, and the Bristol Deaf and Dumb Institution will each receive one part.-By the will of the late Mr. G. S. Guy the testator left $£ 500$ each to the Malvern Hospital, the Wolverhampton Royal Orphanage, and the Wednesbury District Nurses' Institution or Nurses' Home. Mr. Austen Chamberlain has received a sum of $£ 2004$ from Messrs. F. and A. Swanzy, Limited, being their collection on behalf of the fund which is being raised for the extension of the London School of Tropical Medicine.-The Grand Duke Michael has sent a cheque for 500 guineas to the Hampstead and North-West London Hospital for the purpose of pur chasing a motor ambulance.

\section{HYPERTROPHIC STENOSIS OF THE PYLORUS IN ADULTS.}

BY H. GILBERT BARLING, M.B. LoND., F.R.C.S. ENG.,

PROFESSOR OF SURGERY IN THE UNIVERSITY OF BIRMINGHAM; SURGEON TO THE GENERAL HOSPITAL, BIRMINGHAM.

I suppose that most surgeons who have had to deal with cases of hypertrophic pyloric stenosis in the infant have wondered what happens to the muscular overgrowth in the pyloric canal, whether the patients are submitted to opera. tion or recover without. Does the hypertrophy eventually recede or does it remain permanent? May it become exaggerated later in life and produce symptoms, or may it originate in adults? The following cases seem worth recording as a small contribution toward furnishing an answer to these questions,

CASE 1.-In January, 1909, a male aged 27, was admitted under my care in the General Hospital, Birmingham, with symptoms typical of pyloric stenosis-periodic vomiting of large quantities of fluid, evidence of stasis, loss of weight, and severe constipation. The illness began three years before admission with indigestion, which the patient described as pain in his stomach almost as soon as he had taken his food, a feeling of fulness, and much flatulence. These conditions would come on in attacks lasting two or three weeks, and were relieved by medicine. After an attack he would be all right, perhaps for two or three months, and would then have another similar attack. The pain was felt below the left costal margin; it would last from half an hour to an hour, and would gradually go off. When these symptoms had existed two years the patient began to vomit after taking food; at first it was usually after his midday meal, and the vomiting came on almost immediately after the food was taken; the vomited matter appeared to be the food very little altered. After the act of romiting the patient felt quite comfortab le and well. The intervals between the attacks of vomiting gradually became shorter, until erentually the vomiting occurred after taking even fluids. Blood had never been noticed in the vomit or in the stools.

Operation. - The stomach was comparativeìy small, but its muscular coats were very hypertrophied. A firm, massive thickening involved the whole of the pyloric canal, and encroached a little on the antrum. The thickening felt like a solid muscular structure such as the body of the uterus; it was nearly three inches long and about an inch and a hal thick; the peritoneum over the thickening was perfectly normal; the surface was smooth and without scar or nodu. lations. On attempting to invaginate the stomach or duodenum into the pyloric channel only the very tip of the little finger was admitted from either side. These conditions were verified by my assistant at the time of the operation, and we agreed that they could not be explained by any spasmodic contraction, nor did they suggest malignant growth or inflammatory formation, but rather an overgrowth of muscular or fibrous tissue. A posterior gastrojejunostomy by the no-loop method was performed, and an easy recovery followed. I learn from $\mathrm{Mr}$. E. H. Kenderdine, of Coventry, that the patient continues well and in full $w$ ork-that is, nearly four years after the operation.

The conditions found suggested to me that the patient was suffering from a hypertrophic stenosis similar to that which occurs in young infants, and I have deferred recording the case, thinking that time might bring other examples of the same condition.

CASE 2.-Early in January, 1912, I was asked by my colleague, Sir Robert M. Simon, to see with him a girl, 17 years of age, who had been admitted into his wards complaining of pain in the upper abdomen and romiting. Her illness dated from a time six months previous to admission to hospital, when she vomited after eating some fried fish; she was ill for a week, and then was able to return to work. $\mathbf{A}$ fortnight later the pain and vomiting after food returned and continued with intermissions until admission to hospital. 
When admitted the pain came on from half an hour to an hour after food; the vomiting was frequent and was preceded by retching; blood had never been recognised in the vomited matter.

General state. - The patient was thin and pallid; the cheeks were flushed; the left pupil was larger than the right; the mental state was dull, and she spent much time in sleeping. The abdomen was scaphoid in shape and moved on respiration; tenderness on palpation was not elicited, and no tumour could be recognised; the bowels were very constipated. A test meal showed the presence of unaltered currants and muscle fibre some six hours after the meal was given. The vomited matter was generally very disagreeable in odour, but repeated examination failed to show the presence of blood. A bismuth meal administered for $\mathbf{X}$ ray examination was vomited almost immediately. fixation on adjacent parts. The usual operation of posterior gastro-jejunostomy was performed. The operation was well borne, but on Jan. 17 th a slight convergent strabismus was noticed, and the patient complained of diplopia. On the 19th she had vertical nystagmus, and on the 24 th complained of pain in the right side of the abdomen, and a little blood was noticed in the urine; the blood increased in amount the next day or two. On the 26th optic neuritis was observed, and on that day tubercle bacilli were found in the urine. Vomiting did not occur for the first few days after the operation, but subsequently it happened at rare intervals. The patient died on Jan. 31st apparently from tubercular meningitis. No complete necropsy was allowed, so the stomach only was examined.

For the illustration I am indebted to $\mathrm{my}$ dresser, $\mathrm{Mr}_{\text {. }}$ Oscar Parkes. It shows the first part of the duodenum, the

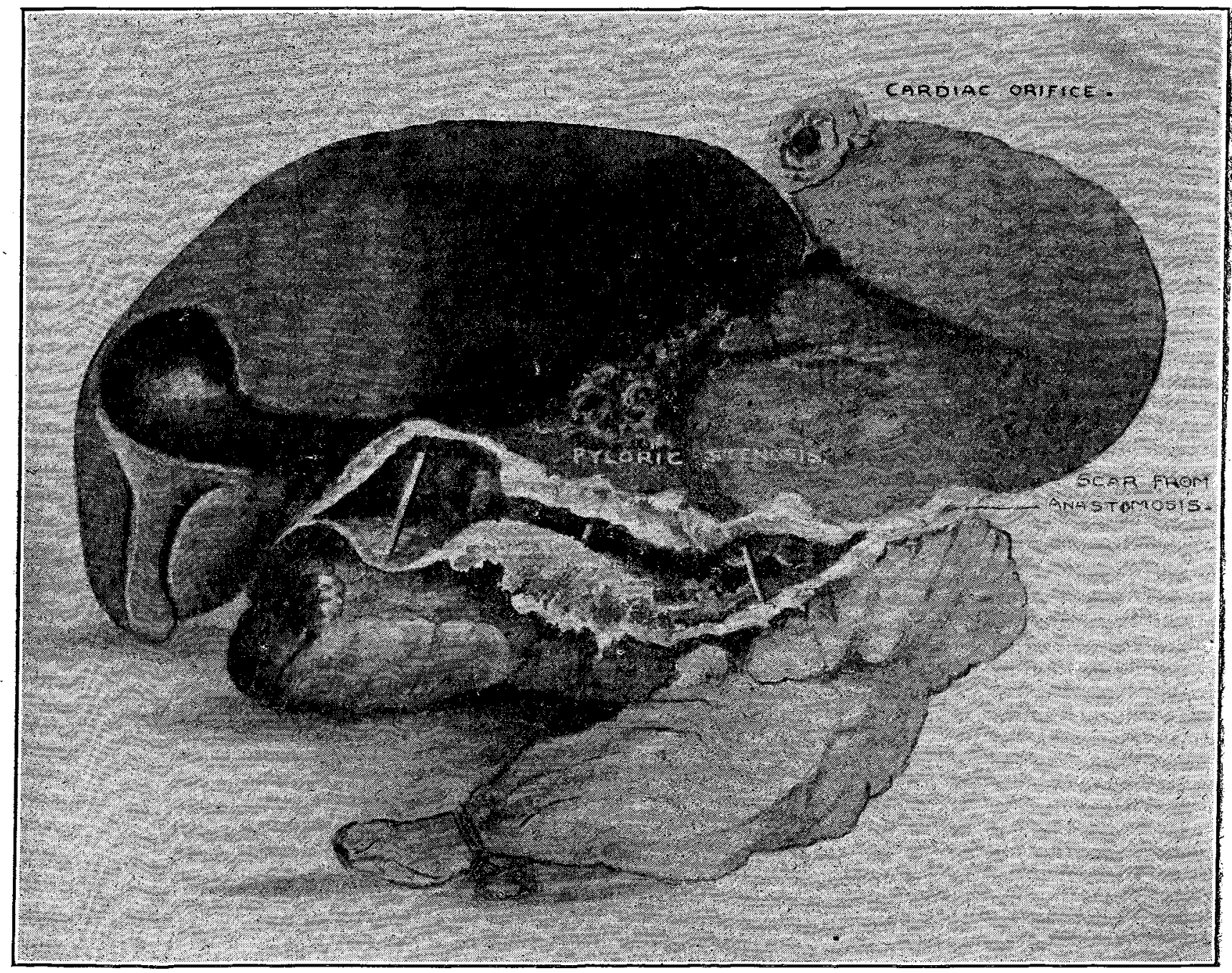

Sketch of stomach and duodenum, laid open to show hypertrophic stenosis of pylorus.

Von Pirquet reaction was negative; the leucocyte count was 10,000. The temperature was irregular; sometimes it ran up to as high as $103^{\circ} \mathrm{F}$.; the pulse was irregular and generally quick. The girl was evidently very ill, more so than one would generally expect to find in a case merely of simple stenosis of the pylorus, and both Sir Robert Simon and myself thought, from the character of the vomit and from the patient's general condition, that it was possible she was suffering from a stenosis in the small intestine rather than at the pylorus, and we were suspicious that the condition might be one of tubercular constriction from past ulceration of the bowel.

Operation (Jan. 15th).-The pyloric canal presented a dense thickening sharply limited at both ends and resembling exactly the hypertrophic stenosis of young infants. The peritoneal surface was quite smooth and free from any indication of ulceration; there was no nodulation and no pyloric canal, and the adjacent part of the stomach laid open; the overgrowth of tissue in the pyloric canal and its abrupt limits are well seen. Careful examination of the exposed mucous membrane showed no trace of old or reeent ulceration, and microscopic section revealed only an overgrowth of the circular muscular fibres. The thickening of the pyloric canal in the first case was much more marked than in the second, and allowing for the difference in size of the organs compared, it was an exaggeration of the infantile condition.

When operation revealed the cause of the patients? symptoms the near relatives of each patient were carefully questioned as to the history during infancy, but no facts were obtained suggesting the presence of stenosis in the patients' lives at an earlier date than that recorded in the preceding notes.

Birminghan. 